\title{
PENGARUH PERSEDIAAN TERHADAP LABA MELALUI PENJUALAN PADA CV. RIZKY BIKE INDRAMAYU
}

\author{
The effect of inventory of profit to sales at CV. Rizky Bike Indramayu \\ Andi Wahyu Hidayat, Nandan A Hidayat \\ Manajemen FE Unwir \\ nandanhidayatfe@gmail.com
}

\begin{abstract}
ABSTRAK
Penelitian ini bertujuan untuk mengetahui adanya pengaruh persediaan terhadap laba melalui penjualan. Metode pengumpulan data digunakan dengan cara observasi dan wawancara. Data yang diperoleh berupa laporan keuangan perusahaan yaitu neraca dan laporan laba/rugi dari tahun 2010 - 2015. Hasil penelitian menunjukan bahwa :

Hasil analisis korelasi antara X1 terhadap X2 sebesar $r=0,270$ dan termasuk dalam kategori rendah yang bersifat positif sempurna (searah). Hasil korelasi antara X2 terhadap $Y$ sebesar $r=$ 0,601 dan termasuk dalam kategori kuat yang bersifat positif sempurna (searah). Sedangkan hasil korelasi antara X1 terhadap $Y$ sebesar $r=$ 0,576 dan termasuk dalam kategori sedang yang bersifat positif sempurna (searah).
\end{abstract}

Hasil analisis determinasi antara X1 terhadap $\mathrm{X} 2$ sebesar $\mathrm{Kd}=\mathbf{7 , 3 1 \%}$ yang berarti persediaan mempunyai kontribusi $7,31 \%$ terhadap penjualan sedangkan sisanya $92,69 \%$ dipengaruhi oleh faktor lain yang tidak diteliti. Hasil analisis determinasi $\mathrm{X} 2$ terhadap $\mathrm{Y}$ sebesar $\mathrm{Kd}=\mathbf{3 6 , 1 0 \%}$ yang berarti $X 2$ mempunyai kontribusi $36 \%$ terhadap $Y$ sedangkan sisanya $63,90 \%$ dipengaruhi oleh faktor lain yang tidak diteliti. Sedangkan hasil analisis determinasi X1 terhadap Y sebesar $\mathrm{Kd}=\mathbf{3 3 , 2 0 \%}$ yang berarti X1 mempunyai kontribusi 33,20\% terhadap $Y$ sedangkan sisanya $\mathbf{6 6 , 8 0 \%}$ dipengaruhi oleh faktor lain yang tidak diteliti.

Hasil analisis uji hipotesis (uji t) antara X1 terhadap X2 sebesar thitung $=\mathbf{0 , 5 6 2}$ sedangkan ttabel $=2,312$ yang berarti thitung $<$ ttabel maka kriterianya adalah Ha ditolak dan Ho diterima. Hasil analisis uji hipotesis (uji t) antara X2 terhadap $Y$ thitung $=1,503$ sedangkan tabel $=$ 0,569 yang berarti thitung< ttabel maka kriterianya adalah Ho ditolak dan Ha diterima. Sedangkan Hasil analisis uji hipotesis (uji t) antara $\mathrm{X} 1$ terhadap $\mathrm{Y}$ thitung $=1,410$ sedangkan ttabel $=$ 0,569 yang berarti thitung $<$ ttabel maka kriterianya adalah Ho ditolak dan Ha diterima.
Kata Kunci: Persediaan, Penjualan, laba.

\section{ABSTRACT}

This study aimed to investigate the effect of inventory of provit to sales. Data collection method used by observation and interview. Data obtained in the form of the company financial statements is balance sheet and profit/loss from $2010-2015$. The results showed that :

The results of corellation analysis between the X1 of $X 2$ is $r=0,270$ included in the category of low which is a perfect positive (inverted). The results of corellation analysis between the $\mathrm{X} 2$ of $\mathrm{Y}$ is $r=0,601$ included in the category of strong which is a positive perfect (inverted). while the results of corellation analysis between the $\mathrm{X} 1$ of $\mathrm{Y}$ is $r=0,576$ included in the category of medium which is a positive perfect (inverted).

The results of determination analysis between the $\mathrm{X} 1$ of fixed assets to $\mathrm{X} 2$ is $\mathrm{Kd}=\mathbf{7 , 3 1 \%}$ which means that the X1 has contributed $7,31 \%$ to X2 $92,69 \%$ the rest is affected by other factor not researched. The $\mathrm{X} 1$ between the $\mathrm{Y}$ is $\mathrm{Kd}=\mathbf{3 6 , 1 0 \%}$ which means that the $Y$ has contributed $36,10 \%$ to liquidity while $63,90 \%$ the rest is affected by other factor not researched. While the $\mathrm{X} 1$ between the $\mathrm{Y}$ is $\mathrm{Kd}=$ $33,20 \%$ which means that the $Y$ has contributed $33,20 \%$ to liquidity while $66,80 \%$ the rest is affected by other factor not researched.

The results of the analysis of hipotests test ( $t$ test) between the $\mathrm{X} 1$ to $\mathrm{X} 2$ is taritmethic $=0,562$ while ttable $=2,312$ which is taritmethic $<$ ttable than $\mathrm{Ha}$ rejectted and $\mathrm{Ho}$ accepted. The results of the analysis of hipotesis test $(t$ test) between the $\mathrm{X} 2$ to $Y$ is is taritmethic $=1,503$ while table $=0,569$ which is taritmethic > ttable than Ho rejected and Ho accepted. While the results of the analysis of hipotesis test (t test) between the $\mathrm{X} 1$ to $\mathrm{Y}$ is is taritmethic $=1,410$ while ttable $=0,569$ which is taritmethic > ttable than $\mathrm{Ho}$ rejected and $\mathrm{Ho}$ accepted.

Keywords: Inventory, sales, Profit 


\section{PENDAHULUAN}

Jumlah persediaan menentukan tingkat penjualan bagi perusahaan, semakin banyak permintaan barang maka persediaan pun harus mencukupi terhadap permintaan tersebut, tanpa adanya persediaan, para pengusaha akan dihadapkan pada resiko bahwa perusahaannya pada suatu waktu tidak dapat memenuhi keinginan para pelanggannya. Keberhasilan perusahaan tergantung terhadap penjualan. Dan penjualan dapat mendongkrak pendapatan perusahaan hingga tujuan perusahaan untuk memperoleh laba dapat tercapai. Peningkatan penjualan ini akan mempengaruhi peningkatan persediaan barang. CV RIZKY BIKE harus mengelola dan mengembangkan usahanya dalam meningkatkan penjualan setiap periodenya agar perusahaan tetap berjalan dan mampu menghasilkan laba. Maka perlu dilakukan penelitian mengenai persediaan, laba dan penjualan

\section{Rumusan Masalah}

1. Bagaimana persediaan di CV RIZKY BIKE?

2. Bagaimana penjualan di CV RIZKY BIKE?

3. Bagaimana laba yang diperoleh di $\mathrm{CV}$ RIZKY BIKE?

4. Bagaimana pengaruh persediaan terhadap penjualan di CV RIZKY BIKE?

5. Bagaimana pengaruh penjualan terhadap laba di CV RIZKY BIKE?
6. Bagaimana pengaruh persediaan terhadap laba melalui penjualan di $\mathrm{CV}$ RIZKY BIKE?

\section{Tujuan Penelitian}

1. Untuk mengetahui persediaan di $\mathrm{CV}$ RIZKY BIKE

2. Untuk mengetahui penjualan di $\mathrm{CV}$ RIZKY BIKE

3. Untuk mengetahui laba yang diperoleh di CV RIZKY BIKE

4. Untuk mengetahui pengaruh persediaan terhadap penjualan di CV RIZKY BIKE

5. Untuk mengetahui pengaruh penjualan terhadap laba di CV RIZKY BIKE

6. Untuk mengetahui pengaruh persediaan terhadap laba melalui penjualan di CV RIZKY BIKE.

\section{TINJAUAN PUSTAKA}

\section{Persediaan}

Menurut Sri Dwi Ari Ambarwati (2010:141): Persediaan merupakan bentuk investasi yang sangat penting bagi sebuah perusahaan.

Menurut Zaki Baridwan (2008:149), menyatakan bahwa: Persediaan perusahaan dagangan adalah perusahaan yang membeli barang dan menjualnya kembali tanpa mengadakan perubahan bentuk barang.

Menurut Sutrisno (2012:91), menyatakan bahwa: Persediaan adalah sejumlah barang atau bahan yang dimiliki oleh perusahaan yang tujuannya untuk dijual atau diolah kembali. 


\section{Indikator Persediaan}

Menurut Munawir (2008:16) menyatakan bahwa: semua barang - barang yang diperdagangkan yang sampai tanggal neraca masih digudang/belum laku dijual.

Adapun Indikator persediaan dari pengertian diatas adalah :Semua barang barang yang masih digudang/belum laku dijual

Faktor - faktor yang mempengaruhi besarnya persediaan

Menurut Farah Margaretha (2005:146), faktor - faktor yang mempengaruhi persediaan yaitu :Volume penjualan, Jangka waktu proses produksi, Daya tahan/faktor mode produk akhir

\section{Penjualan}

Menurut Kasmir (2009:305), menyatakan bahwa: Penjualan adalah jumlah omzet barang atau jasa yang dijual, baik dalam unit maupun dalam rupiah.

Menurut Mulyadi

(2008:202), menyatakan bahwa: Penjualan merupakan kegiatan yang di lakukan oleh penjual dalam menjual barang atau jasa dengan harapan akan memperoleh laba dari adanya transaksi transaksi tersebut dan penjualan dapat di artikan sebagai pengalihan atau pemindahan hak kepemilikan atas barang atau jasa dari pihak penjual ke pembeli.

Menurut Irham Fahmi (2014:68), menyatakan bahwa: Salles atau penjualan adalah penerimaan yang diperoleh dari hasil penjualan produk seperti pengiriman barang (goods) atau pemberian jasa (service) yang diberikan.

\section{Indikator penjualan}

Menurut Hery (2014:123) indikator penjualan adalah: Penjualan merupakan total jumlah yang dibebankan kepada pelanggan atas barang dagangan yang dijual perusahaan, baik meliputi penjualan tunai maupun penjualan kredit. Penjualan dikurangi dengan retur dan penyewaan harga jual dan potongan penjualan akan diperoleh penjualan bersih (net sales).

Adapun indikator penjualan dari pegertian diatas adalah :Total jumlah yang dibebankan kepada pelanggan, Barang dagangan yang dijual perusahaan, Penjualan tunai maupun penjualan kredit, Retur dan penyewaan harga jual, Potongan penjualan

\section{Faktor-faktor yang Mempengaruhi Penjualan}

Menurut Basu Swastha (2012:129), menyatakan bahwa penjualan dipengaruhi oleh beberapa faktor, diantaranya:Kondisi dan Kemampuan Penjual, Kondisi Pasar, Modal, Kondisi Organisasi Perusahaan, Faktor Lain (periklanan, kampanye, pemberiaan hadiah)

\section{Laba}

Menurut Zaki Baridwan (2008:29), yaitu : Kenaikan modal (aktiva bersih) yang berasal dari transaksi sampingan atau transaksi yang jarang terjadi dari suatu badan usaha, dan dari seтиa transaksi atau kejadian lain yang mempengaruhi badan usaha selama periode 
kecuali yang timbul dari pendapatan (revenue) atau investasi oleh pemilik.

Menurut Kasmir (2009:45) menyatakan bahwa : Jika jumlah pendapatan lebih besar dari jumlah biaya, dikatakan perusahaan dalam kondisi laba (untung).

Menurut

M.

Nafarin

(2013:788),menyatakan

bahwa: $\quad L a b a$

(income) adalah perbedaan antara pendapatan dengan keseimbangan biayabiaya dan pengeluaran untuk periode tertentu.

Indikator Laba

Menurut Sadono Sukirno (2010:32), yaitu: Laba merupakan ukuran keseluruhan prestasi perusahaan yang di definisikan sebagai: $l a b a=$ penjualan - biaya

Adapun indikator laba adalah :

$$
\text { Laba }=\text { Penjualan }- \text { Biaya }
$$

Faktor - faktor yang mempengaruhi laba

Menurut Abdul Hakim dan Bambang Supono (2012:73), yaitu: Factor-faktor yang mempengaruhi laba antara lain: Biaya, Harga jual produk, Volume (penjualan dan produksi)

Hubungan dan Pengaruh Antar Variabel

Hubungan dan Pengaruh antara Persediaan terhadap Penjualan
Dikutip dari buku dasar - dasar pembelanjaan perusahaan Bambang Riyanto (2010:85), yang menyatakan bahwa:

"penjualan kredit tidak segera menghasilkan penerimaan kas, tetapi menimbulkan piutang langganan, dan barulah kemudian pada hari jatuhnya terjadi aliran kas masuk (cash inflows)yang berasal dari pengumpulan piutang tersebut. Dengan demikian maka piutang (receivable) merupakan elemen modal kerja yang juga selalu dalam keadaan berputar secara terusmenerus dalam rantai perputaran modal kerja, yaitu : kas -> inventory -> piutang -> kas. Dalam keadaan yang normal dan dimana penjualan pada umumnya dilakukan dengan kredit, piutang mempunyai tingkat likuiditas yang lebih tinggi daripada inventory (persediaan), karena perputaran dari piutang ke kas membutuhkan satu langkah saja".

Hubungan dan Pengaruh antara penjualan terhadap laba

Dikutip dari buku analisis laporan keuangan kasmir (2009:305) yang menyatakan bahwa:

"dalam praktiknya perubahan yang terjadi laba disebabkan dua faktor, yaitu: 1). Faktor penjualan dan 2). Faktor harga pokok penjualan

\section{Kerangka Pemikiran}

Menurut R. Agus Sartono (2008;443):

Ditinjau dari segi neraca persediaan adalah barang-barang atau bahan yang masih tersisa pada tanggal neraca, atau barangbarang yang akan segera dijual, digunakan atau diproses dalam periode normal perusahaan. 
Menurut Irham Fahmi (2014:68), menyatakan bahwa: Salles atau penjualan adalah penerimaan yang diperoleh dari hasil penjualan produk seperti pengiriman barang (goods) atau pemberian jasa (service) yang diberikan.

Menurut Kasmir (2009:45) menyatakan bahwa: Jika jumlah pendapatan lebih besar dari jumlah biaya, dikatakan perusahaan dalam kondisi laba (untung)

$H_{1}$

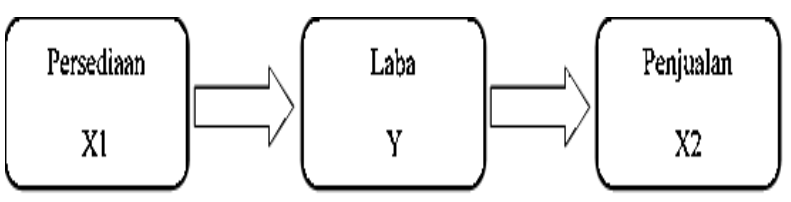

\section{Hipotesis Penelitian}

Peneliti mengajukan hipotesis bahwa:

$\mathrm{H}_{1}$ : Diduga terdapat pengaruh penjualan terhadap laba

$\mathrm{H}_{2}$ : Diduga terdapat pengaruh persediaan terhadap penjualan

$\mathrm{H}_{3}$ : Diduga terdapat pengaruh persediaan terhadap laba melalui penjualan

\section{METODOLOGI PENELITIAN}

Metode ini bertujuan untuk mengetahui hubungan persediaan, Penjualan dan laba di CV. Rizky Bike - Indramayu.

Menurut Ating Somantri dan Sambas Ali Muhidin (2011:19), yang menyatakan bahwa: "Metode deskriptif membahas cara-cara pengumpulan data, penyederhanaan angkaangka pengamatan yang diperoleh (meringkas dan menyajikan), serta melakukan pengukuran lebih menarik, berguna dan mudah dipahami”.

\section{Populasi}

Menurut Sugiyono (2013:61), mengemukakan bahwa:"Populasi adalah wilayah generalisasi yang terdiri atas obyek/subyek yang mempunyai kualitas dan karakteristik tertentu yang ditatapkan oleh peneliti untuk dipelajari dan kemudian ditarik kesimpulannya".

Dalam penelitian ini populasinya adalah semua data keuangan yang terdiri dari persediaan, penjualan dan laba yang diperoleh dengan cara menganalisis laporan laba rugi dan neraca keuangan perusahaan yang dibuat sejak berdirinya CV. Rizky Bike - Indramayu sampai dengan sekarang.

\section{Sampel}

Menurut Sugiyono (2013:62), mengemukakan bahwa:"Sampel adalah bagian dari jumlah dan karakterisitik yang dimiliki oleh populasi”.

Sampel yang diambil dalam penelitian ini adalah laporan laba rugi dan neraca keuangan CV. Rizky Bike - Indramayu selama enam periode terakhir 2010 - 2015 .

\begin{tabular}{|c|c|c|c|}
\hline \multirow{5}{*}{ Metode } & \multicolumn{3}{|c|}{ Operasional Variabel } \\
\hline & Variabel & Indikator & Pengukuran \\
\hline & $\begin{array}{l}\text { Independent } \\
\text { Persediaan }\left(X_{1}\right)\end{array}$ & $\begin{array}{l}\text { 1. Semua barang - barang yang masih } \\
\text { digudang/belum laku dijual } \\
\text { Munawir (2008:16) }\end{array}$ & Rasio \\
\hline & $\begin{array}{l}\text { Independent } \\
\text { Penjualan }\left(X_{2}\right)\end{array}$ & $\begin{array}{l}\text { 1. Total jumlah yang dibebankan } \\
\text { kepada pelanggan } \\
\text { 2. Barang dagangan yang dijual } \\
\text { perusahaan } \\
\text { 3. Penjualan tunai maupun penjualan } \\
\text { kredit } \\
\text { 4. Retur dan penyewaan harga jual } \\
\text { 5. Potongan penjualan } \\
\text { Heri }(2014 ; 123)\end{array}$ & Rasio \\
\hline & $\begin{array}{l}\text { Dependent } \\
\text { Laba }(\mathrm{Y})\end{array}$ & $\begin{array}{l}\text { Laba }=\text { penjualan }- \text { biaya } \\
\text { Sadono Sukirno }(2010: 32)\end{array}$ & Rasio \\
\hline
\end{tabular}




\section{Pengumpulan Data}

Library Research (Penelitian Kepustakaan), Field Research (Penelitian Lapangan) yaitu Wawancara dan Observasi

\section{Teknik Analisis}

\section{Analisis Korelasi}

Teknik korelasi ini digunakan untuk mencari hubungan dan membuktikan hipotesis hubungan dua variabel bila data kedua variabel berbentuk interval atau ratio. Menurut Sugiyono (2013:228), maka Rumus yang digunakan adalah sebagai berikut:

$$
r y=\frac{n \sum x y-\left(\sum x\right)\left(\sum y\right)}{\sqrt{\left\{n \sum x^{2}-\left(\sum x\right)^{2}\right\}\left\{n \sum y^{2}-\left(\sum y\right)^{2}\right\}}}
$$

Di mana:

$\mathrm{r}=$ Koefisien Kolerasi

$r=0$ menyatakan hubungan kedua variable sangat lemah bahkan mungkin tidak mempunyai hubungan sama sekali

$r=-1$ menyatakan kedua variable sangat kuat den bersifat negative (terbalik)

$\mathrm{r}=1$ menyatakan kedua variable sangat kuat dan bersifat positif (searah)

$\mathrm{n}=$ Periode

$\mathrm{X}=$ VariabelBebas

$\mathrm{Y}=$ VariabelTerikat

Nilai $\mathbf{r}$ terbesar adalah $\mathbf{+ 1}$ dan $\mathbf{r}$ terkecil adalah -1. $\mathbf{r}=\mathbf{+ 1}$ menunjukan hubungan positif sempurna, sedangkanr $=\mathbf{- 1}$ menunjukan hubungan negative sempurna. rtidak mempunyai satuan atau dimensi. Tanda + atau - hanya menunjukan arah hubungan.

\section{Analisis Jalur}

Untuk mencari koefisien jalur diperoleh dari persamaan ( Sugiyono, $2012: 297$ ) :

$\mathbf{r}_{21}=\mathbf{p}_{12}$

$\mathbf{r}_{\mathbf{y} 1}=\mathbf{p}_{1 \mathrm{y}}+\mathbf{p}_{2 \mathrm{y}} \cdot \mathbf{r} 21$

$\mathbf{r}_{\mathbf{y} 2}=\mathbf{p}_{1 \mathrm{y}} \cdot \mathbf{r}_{21}+\mathbf{p}_{2 \mathrm{y}}$

keterangan :

$\mathrm{r}_{21}=$ kolerasi $\mathrm{X} 2$ dengan $\mathrm{X} 1$

$\mathrm{p}_{12}=$ nilai koefisien jalur X2dan X1

$\mathrm{r}_{\mathrm{y} 1}=$ kolerasi $\mathrm{Y}$ dengan $\mathrm{X} 1$

$\mathrm{p}_{1 \mathrm{y}}=$ nilai koefisien jalur $\mathrm{Y}$ dan $\mathrm{X} 1$

$\mathrm{p}_{2 \mathrm{y}}=$ nilai koefisien jalur $\mathrm{Y}$ dan $\mathrm{X} 2$

$\mathrm{r}_{\mathrm{y} 2}=$ kolerasi $\mathrm{Y}$ dengan $\mathrm{X} 2$

\section{Analisis Koefisien Determinan}

Menurut Sugiyono

(2011:231), menyatakan bahwa: Koefisien determinasi disebut koefisien penentu, karena varians yang terjadi pada variabel dependen dapat dijelaskan melalui varians yang terjadi pada variabel independen.

$$
\mathrm{Kd}=\mathbf{r}^{2} \times 100 \%
$$

Dimana:

$K d=$ Koefisien determinasi

$r=$ Koefisien korelasi

\section{Analisis Uji Hipotesis}

Uji t

\section{Menurut Sugiyono (2011:230),} menyatakan bahwa rumus uji $\mathrm{t}$ sebagai berikut:

$$
t=\mathrm{r} \frac{\sqrt{\mathrm{n}-2}}{\sqrt{1-\mathrm{r}^{2}}}
$$

Keterangan:

$t=t$ hitung

$r=$ Koefisien Korelasi 
Andi Wahyu Hidayat, Nandan A Hidayat

$n=$ Jumlah data

\section{HASIL DAN PEMBAHASAN}

\section{Hasil Penelitian}

Kondisi Keuangan CV. Rizky Bike

\section{Indramayu}

Sebagaimana halnya perusahaan yang lain, CV. Rizky Bike yang bergerak sebagai sebuah perusahaan yang memiliki tujuan untuk mengoptimalkan laba, sudah tentu melakukan kegiatan pengelolaan keuangan. Adapun keadaan keuangan CV. Rizky Bike mulai tahun 2010 sampai dengan tahun 2015 menggambarkan beberapa tabel berikut:

\section{Tabel 1}

Kondisi Modal Sendiri

Pada CV. Rizky Bike Indramayu Tahun 2010 - 2015

\begin{tabular}{|c|c|c|c|}
\hline TAHUN & MODAL SENDIRI & NAIK/TURUN & PERUBAHAN (\%) \\
\hline 2010 & Rp 1.107.471.000 & & \\
\hline 2011 & Rp 1.113 .000 .000 & Rp $\quad 5.529 .000$ & 0,50 \\
\hline 2012 & Rp 1.123 .316 .000 & Rp 10.316.000 & 0,92 \\
\hline 2013 & Rp 1.129.864.800 & Rp $\quad 6.548 .800$ & 0,58 \\
\hline 2014 & Rp 1.130.901.050 & Rp $\quad 1.036 .250$ & 0,09 \\
\hline 2015 & Rp 1.137.455.550 & $\operatorname{Rp} \quad 6.554 .500$ & 0,58 \\
\hline
\end{tabular}

Tabel 2

Kondisi Aktiva Lancar

Pada CV. Rizky Bike Indramayu

Tahun 2010 - 2015

\begin{tabular}{|c|cc|c|c|}
\hline Tahun & \multicolumn{2}{|c|}{ Aktiva Lancar } & Naik/Turun & Perubahan (\%) \\
\hline 2010 & $\mathrm{Rp}$ & 359.329 .400 & - & - \\
\hline 2011 & $\mathrm{Rp}$ & 364.050 .000 & $\mathrm{Rp} 4.720 .600$ & 1,31 \\
\hline 2012 & $\mathrm{Rp}$ & 365.866 .000 & $\mathrm{Rp} 1.816 .000$ & 0,50 \\
\hline 2013 & $\mathrm{Rp}$ & 366.464 .800 & $\mathrm{Rp} 598.800$ & 0,16 \\
\hline 2014 & $\mathrm{Rp}$ & 368.901 .050 & $\mathrm{Rp} 2.436 .250$ & 0,66 \\
\hline 2015 & $\mathrm{Rp}$ & 374.855 .550 & $\mathrm{Rp} 5.954 .500$ & 1,61 \\
\hline
\end{tabular}

Tabel 3

Kondisi Total Hutang

Pada CV. Rizky Bike Indramayu

Tahun 2010 - 2015

\begin{tabular}{|c|cc|c|c|}
\hline TAHUN & \multicolumn{2}{|c|}{ HUTANG DAGANG } & NAIK/TURUN & PERUBAHAN (\%) \\
\hline 2010 & $\mathrm{Rp}$ & 63.458 .400 & & \\
\hline 2011 & $\mathrm{Rp}$ & 60.650 .000 & $\mathrm{Rp}(2.808 .400)$ & $-4,42$ \\
\hline 2012 & $\mathrm{Rp}$ & 47.150 .000 & $\mathrm{Rp}(13.500 .000)$ & $-22,25$ \\
\hline 2013 & $\mathrm{Rp}$ & 38.800 .000 & $\mathrm{Rp}(8.350 .000)$ & $-17,70$ \\
\hline 2014 & $\mathrm{Rp}$ & 38.200 .000 & $\mathrm{Rp}(600.000)$ & $-1,54$ \\
\hline 2015 & $\mathrm{Rp}$ & 34.400 .000 & $\mathrm{Rp}(3.800 .000)$ & $-9,94$ \\
\hline
\end{tabular}

Tabel 4

Kondisi Total Aktiva

Pada CV. Rizky Bike Indramayu

Tahun 2010 - 2015

\begin{tabular}{|c|c|c|c}
\hline \multirow{2}{*}{ Tahun } & Total aktiva & Naik/Turun & Perubahan (\%) \\
& & & \\
\hline 2010 & $\operatorname{Rp~} 1.170 .929 .400$ & - & - \\
\hline 2011 & $\operatorname{Rp~} 1.173 .650 .000$ & $\operatorname{Rp~2.720.600}$ & 0,23 \\
\hline 2012 & $\operatorname{Rp~} 1.170 .466 .000$ & $\operatorname{Rp}(3.184 .000)$ & $-0,27$ \\
\hline 2013 & $\operatorname{Rp~} 1.168 .664 .800$ & $\operatorname{Rp}(1.801 .200)$ & $-0,15$ \\
\hline 2014 & $\operatorname{Rp} 1.169 .101 .050$ & $\operatorname{Rp} 436.250$ & 0,04 \\
\hline 2015 & $\operatorname{Rp} 1.171 .855 .550$ & $\operatorname{Rp} 2.754 .500$ & 0,24 \\
\hline
\end{tabular}

Tabel 5

Perkembangan Persediaan

CV. Rizky Bike

Tahun 2010 - 2015

\begin{tabular}{|c|r|r|c|}
\hline TAHUN & PERSEDIAAN & NAIK/TURUN & PERUBAHAN (\%) \\
\hline 2010 & $\mathrm{Rp} 40.000 .000$ & & \\
\hline 2011 & $\mathrm{Rp} 52.500 .000$ & 12500000 & 31,25 \\
\hline 2012 & $\mathrm{Rp} 47.350 .000$ & -5150000 & $-9,81$ \\
\hline 2013 & $\mathrm{Rp} 49.350 .000$ & 2000000 & 4,22 \\
\hline 2014 & $\mathrm{Rp} 51.750 .000$ & 2400000 & 4,86 \\
\hline 2015 & $\mathrm{Rp} 53.650 .000$ & 1900000 & 3,67 \\
\hline
\end{tabular}

Tabel 6

Perkembangan Penjualan

CV. Rizky Bike

Tahun 2010 - 2015

\begin{tabular}{|c|c|r|c|}
\hline TAHUN & PENJUALAN & NAIK/TURUN & PERUBAHAN (\%) \\
\hline 2010 & $\operatorname{Rp} 722.400 .000$ & & \\
\hline 2011 & $\operatorname{Rp} 743.800 .000$ & 21400000 & 2,96 \\
\hline 2012 & $\operatorname{Rp} 728.700 .000$ & -15100000 & $-2,03$ \\
\hline 2013 & $\operatorname{Rp} 690.900 .000$ & -37800000 & $-5,19$ \\
\hline 2014 & $\operatorname{Rp} 705.600 .000$ & 14700000 & 2,13 \\
\hline 2015 & $\operatorname{Rp} 756.000 .000$ & 50400000 & 7,14 \\
\hline
\end{tabular}

Tabel 7

Laba

CV. Rizky Bike

Tahun 2010 - 2015

\begin{tabular}{|c|l|r|c|}
\hline TAHUN & LABA & NAIK/TURUN & PERUBAHAN (\%) \\
\hline 2010 & $\operatorname{Rp} 240.102 .000$ & & \\
\hline 2011 & $\operatorname{Rp} 244.332 .000$ & 4230000 & 1,76 \\
\hline 2012 & $\operatorname{Rp} 249.060 .000$ & 4728000 & 1,94 \\
\hline 2013 & $\operatorname{Rp} 239.319 .000$ & -9741000 & $-3,91$ \\
\hline 2014 & $\operatorname{Rp} 248.010 .000$ & 8691000 & 3,63 \\
\hline 2015 & $\operatorname{Rp} 251.874 .000$ & 3864000 & 1,56 \\
\hline
\end{tabular}


TABEL 8

TABEL PEMOTONG UNTUK KOEFISIEN KORELASI PERSEDIAAN TERHADAP PENJUALAN

\begin{tabular}{|c|c|c|c|c|c|}
\hline $\mathrm{N}$ & $\mathrm{X} 1$ & $\mathrm{X} 2$ & $\mathrm{X}^{2}$ & $\mathrm{X} 2^{2}$ & $\mathrm{X} 1 . \mathrm{X} 2$ \\
\hline $\mathrm{l}$ & 40 & 722 & 1600 & 521862 & 28896 \\
\hline 2 & 53 & 744 & 2756 & 553238 & 39050 \\
\hline 3 & 47 & 729 & 2242 & 531004 & 34504 \\
\hline 4 & 49 & 691 & 2435 & 477343 & 34096 \\
\hline 5 & 52 & 706 & 2678 & 497871 & 36515 \\
\hline 6 & 54 & 756 & 2878 & 571536 & 40559 \\
\hline JUMLAH & 295 & 4347 & 14590 & 3152854 & 213620 \\
\hline
\end{tabular}

$$
r=\frac{\mathrm{n} \sum \mathrm{X} 1 \mathrm{X} 2-\left(\sum \mathrm{X} 1\right)\left(\sum \mathrm{X} 2\right)}{\sqrt{\left.\left(\mathrm{n} \sum \mathrm{X}^{2}\right)-\left(\sum \mathrm{X}\right)^{2}\right)\left(\mathrm{n} \sum \mathrm{X} 2^{2}-\left(\sum \mathrm{X} 2\right)^{2}\right)}}
$$$$
=\frac{6.213620-(295)(4347)}{\sqrt{\left.(6.14590)-(295)^{2}\right)(6.3152854)}}
$$$$
=\frac{\sqrt{\left.\left.(6.14590)-(295)^{2}\right)(6.3152854)-(4347)^{2}\right)}}{\sqrt{1280744}}
$$$$
=\frac{1281717-1280744}{\sqrt{(87540-86789)(18917124-18899887)}}
$$$$
=\frac{973}{\sqrt{(751)(17238)}}
$$$$
=\frac{973}{\sqrt{12950954}}
$$$$
=\frac{973}{2599}=0,270 \text { (rendah) }
$$

TABEL 9

TABEL PEMOTONG UNTUK KOEFISIEN KORELASI PENJUALAN TERHADAP LABA

\begin{tabular}{|c|c|c|c|c|c|}
\hline $\mathrm{N}$ & $\mathrm{X} 2$ & $\mathrm{Y}$ & $\mathrm{X}^{2}$ & $\mathrm{Y}^{2}$ & $\mathrm{X} 2 . \mathrm{Y}$ \\
\hline 1 & 722 & 240 & 521862 & 57649 & 173450 \\
\hline 2 & 744 & 244 & 553238 & 59698 & 181734 \\
\hline 3 & 729 & 249 & 531004 & 62031 & 181490 \\
\hline 4 & 691 & 239 & 477343 & 57274 & 165345 \\
\hline 5 & 706 & 248 & 497871 & 61509 & 174996 \\
\hline 6 & 756 & 252 & 571536 & 63441 & 190417 \\
\hline JUMLAH & 4347 & 1473 & 3152854 & 361601 & 1067432 \\
\hline
\end{tabular}

$$
\begin{aligned}
& r=\frac{\mathrm{n} \sum \mathrm{X} 2 \mathrm{Y}-\left(\sum \mathrm{X} 2\right)\left(\sum \mathrm{Y}\right)}{\sqrt{\left.\left(\mathrm{n} \sum \mathrm{X} 2^{2}\right)-\left(\sum \mathrm{X} 2\right)^{2}\right)\left(\mathrm{n} \sum \mathrm{Y}^{2}-\left(\sum \mathrm{Y}\right)^{2}\right)}} \\
& =\frac{6.1067432-(4347)(1473)}{\sqrt{\left.\left.(6.3152854)-(4347)^{2}\right)(6.361601)-(1473)^{2}\right)}} \\
& =\frac{6404592-6402403}{\sqrt{(18917124-18899887)(2169606-2168836)}}
\end{aligned}
$$

$$
\begin{aligned}
& =\frac{2189}{\sqrt{(17238)(770)}} \\
& =\frac{2189}{\sqrt{13268849}} \\
& =\frac{2189}{3643} \\
& =0,601 \text { (sedang) }
\end{aligned}
$$

TABEL 10

TABEL PEMOTONG UNTUK KOEFISIEN KORELASI PERSEDIAAN TERHADAP LABA

\begin{tabular}{|c|c|c|c|c|c|}
\hline $\mathrm{N}$ & $\mathrm{X} 1$ & $\mathrm{Y}$ & $\mathrm{X}^{2}$ & $\mathrm{Y}^{2}$ & $\mathrm{X} 1 . \mathrm{Y}$ \\
\hline 1 & 40 & 240 & 1600 & 57649 & 9604 \\
\hline 2 & 53 & 244 & 2756 & 59698 & 12827 \\
\hline 3 & 47 & 249 & 2242 & 62031 & 11793 \\
\hline 4 & 49 & 239 & 2435 & 57274 & 11810 \\
\hline 5 & 52 & 248 & 2678 & 61509 & 12835 \\
\hline 6 & 54 & 252 & 2878 & 63441 & 13513 \\
\hline JUMLAH & 295 & 1473 & 14590 & 361601 & 72382 \\
\hline
\end{tabular}

$$
\begin{aligned}
& r=\frac{\mathrm{n} \sum \mathrm{X} 1 \mathrm{Y}-\left(\sum \mathrm{X} 1\right)\left(\sum \mathrm{Y}\right)}{\sqrt{\left.\left(\mathrm{n} \sum \mathrm{X} 1^{2}\right)-\left(\sum \mathrm{X} 1\right)^{2}\right)\left(\mathrm{n} \sum \mathrm{Y}^{2}-\left(\sum \mathrm{Y}\right)^{2}\right)}} \\
& =\frac{6.72382-(295)(1473)}{\sqrt{\left.\left.(6.14590)-(295)^{2}\right)(6.361601)-(1473)^{2}\right)}} \\
& =\frac{434295-433857}{\sqrt{(87540-86789)(2169606-2168836)}} \\
& =\frac{438}{\sqrt{(751)(770)}} \\
& =\frac{438}{\sqrt{578338}} \\
& =\frac{438}{760} \\
& =0,576 \text { (sedang) }
\end{aligned}
$$

\section{Analisis Jalur}

Untuk mencari koefisien jalur diperoleh dari persamaan

$$
\begin{aligned}
& r_{21}=p_{12} \\
& r_{y 1}=p_{1 y}+p_{2 y} \cdot r_{21} \\
& r_{y 2}=p_{1 y} \cdot r_{21}+p_{2 y}
\end{aligned}
$$

\section{Mencari nilai koefisien jalur p1y}

$$
\begin{aligned}
& \mathrm{p}_{1 \mathrm{y}}=\frac{\left[\begin{array}{ll}
r_{y 1} & r_{21} \\
r_{y 2} & 1
\end{array}\right]}{\left[\begin{array}{cc}
1,00 & r_{21} \\
r_{21} & 1
\end{array}\right]} \\
& \mathrm{p}_{1 \mathrm{y}}=\frac{\left[\begin{array}{cc}
0.270 & 0.576 \\
0.601 & 1
\end{array}\right]}{\left[\begin{array}{cc}
1 & 0.576 \\
0.576 & 1
\end{array}\right]} \\
& \mathrm{p}_{1 \mathrm{y}}=\frac{[0,093]}{[0.332]} \\
& \mathrm{p}_{1 \mathrm{y}}=0,282
\end{aligned}
$$

Dari perhitungan diatas diperoleh $\mathrm{p}_{1 \mathrm{y}}=$ 0,282 artinya persediaan pada CV. Rizky 
Bike berpengaruh pada laba dan termasuk dalam kategori rendah.

\section{Mencari nilai koefisien jalur $\mathbf{p}_{2 \mathrm{y}}$}

$$
\begin{aligned}
\mathrm{p}_{2 y} & =\frac{\left[\begin{array}{cc}
1 & r_{y 1} \\
r_{21} & r_{y 2}
\end{array}\right]}{\left[\begin{array}{cc}
1 & r_{21} \\
r_{21} & 1
\end{array}\right]} \\
\mathrm{p}_{2 y} & =\frac{\left[\begin{array}{cc}
1 & 0,567 \\
0.567 & 0.601
\end{array}\right]}{\left[\begin{array}{cc}
1 & 0.576 \\
0.576 & 1
\end{array}\right]} \\
\mathrm{p}_{2 y} & =\frac{0.199}{0.332} \\
\mathrm{p}_{2 y} & =0.601
\end{aligned}
$$

Dari perhitungan diatas diperoleh $\mathrm{p}_{2 \mathrm{y}}=$ 0.601 artinya penjualan pada CV. Rizky Bike berpengaruh pada Laba dan termasuk dalam kategori sedang

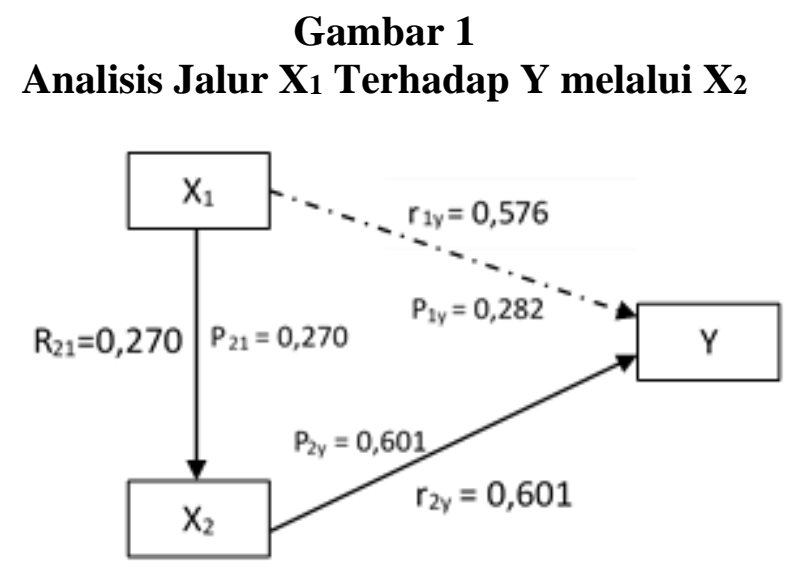

\section{Korelasi $\mathrm{X}_{1}$ terhadap Y melalui $\mathrm{X}_{2}$}

$P_{\text {intervening }}=\mathrm{p}_{1 \mathrm{y}}+\mathrm{p}_{2 \mathrm{y}} \cdot \mathrm{r}_{12}$

$P_{\text {intervening }}=0,282+(0,601)(0,270)$

$P_{\text {intervening }}=0,282+0,162$

$\mathrm{P}_{\text {intervening }}=0,444$

Dari perhitungan diatas diperoleh $P_{\text {intervening }}=0,444$ artinya persediaan terhadap laba melalui penjualan pada CV. Rizky Bike Indramayu berpengaruh dan termasuk dalam kategori sedang.

Korelasi $\mathrm{X}_{1}$ terhadap $\mathrm{Y}$ melalui $\mathrm{X}_{2}$ secara total

$\mathrm{P}$ total $=\mathrm{p}_{21}+\left(\mathrm{p}_{\text {intervening }} \cdot \mathrm{py}_{2}\right)$

$$
\begin{aligned}
& =0,270+(0,444 \cdot 0,601) \\
& =0,270+0,267
\end{aligned}
$$

$$
=0,537
$$

Dari perhitungan diatas diperoleh $\mathrm{P}_{\text {intervening }}=0,537$ artinya persediaan terhadap laba melalui penjualan pada CV. Rizky Bike Indramayu berpengaruh dan termasuk dalam kategori sedang.

\section{Analisis Koefisien Determinasi Persediaan}

\section{Terhadap Penjualan.}

Untuk mengukur berapa besar kontribusi pengaruh persediaan terhadap penjualan, maka digunakan perhitungan koefisien determinasi, yaitu sebagai berikut :

$$
\begin{aligned}
& \mathrm{kd}=\mathrm{r}^{2} \times 100 \% \\
& \mathrm{kd}=0,073 \times 100 \% \\
& \mathrm{kd}=7,31 \%
\end{aligned}
$$

Berdasarkan perhitungan diatas, hasil koefisien determinasi sebesar 7,31\%. Hal ini menunjukan bahwa penjualan dipengaruhi persediaan sebesar $7,31 \%$ sedangkan sisanya 92,69\% dipengaruhi faktor lain, yang tidak diteliti.

\section{Analisis Koefisien Determinasi Penjualan Terhadap Laba.}

Untuk mengukur berapa besar kontribusi pengaruh penjualan terhadap laba, maka digunakan perhitungan koefisien determinasi, yaitu sebagai berikut :

$k d=r^{2} \times 100 \%$

$\mathrm{kd}=0,361 \times 100 \%$

$\mathrm{kd}=36,10 \%$

Berdasarkan perhitungan diatas, hasil koefisien determinasi sebesar 36,10\%. Hal ini menunjukan bahwa penjualan dipengaruhi persediaan sebesar $36,10 \%$ sedangkan 
sisanya $63,90 \%$ dipengaruhi faktor lain, yang tidak diteliti.

\section{Analisis Koefisien Determinasi Persediaan}

\section{Terhadap Laba.}

$\mathrm{kd}=\mathrm{r}^{2} \mathrm{x} 100 \%$

$\mathrm{kd}=0,332 \times 100 \%$

$\mathrm{kd}=33,20 \%$

Berdasarkan perhitungan diatas, hasil koefisien determinasi sebesar $33,20 \%$. Hal ini menunjukan bahwa laba dipengaruhi persediaan sebesar $33,20 \%$ sedangkan sisanya $66,80 \%$ dipengaruhi faktor lain, yang tidak diteliti.

\section{Uji Hipotesis Pengaruh Persediaan}

\section{Terhadap Penjualan.}

berdasarkan data yang diperoleh maka besarnya $t$ adalah sebagai berikut :

$$
\begin{aligned}
& \mathrm{T}_{\text {hitung }}=\frac{\mathrm{r} \sqrt{\mathrm{n}-2}}{\sqrt{1-(r)^{2}}} \\
& \mathrm{~T}_{\text {hitung }}=\frac{0,270 \sqrt{6-2}}{\sqrt{1-(0,270)^{2}}} \\
& \mathrm{~T}_{\text {hitung }}=0,562
\end{aligned}
$$

karena $\mathrm{T}_{\text {hitung }}<$ Ttabel $(0,562<2,312)$, maka $\mathrm{H}_{1 \mathrm{o}}$ diterima $\mathrm{H}_{1 \mathrm{a}}$ ditolak, artinya persediaan terhadap penjualan tidak berpengaruh.

\section{Uji Hipotesis Pengaruh Penjualan}

\section{Terhadap Laba.}

$$
\begin{aligned}
\mathrm{T}_{\text {hitung }} & =\frac{\mathrm{r} \sqrt{\mathrm{n}-2}}{\sqrt{1-(r)^{2}}} \\
\mathrm{~T}_{\text {hitung }} & =\frac{0,601 \sqrt{6-2}}{\sqrt{1-(0,601)^{2}}} \\
\mathrm{~T}_{\text {hitung }} & =1,503
\end{aligned}
$$

karena $\mathrm{T}_{\text {hitung }}>$ Ttabel $(1,503>0,569)$, maka $\mathrm{H}_{2 \mathrm{o}}$ ditolak sedangkan $\mathrm{H}_{2 \mathrm{a}}$ diterima, artinya penjualan terhadap laba berpengaruh.

\section{Uji Hipotesis Pengaruh Persediaan Terhadap Laba.}

$\mathrm{T}_{\text {hitung }}=\frac{\mathrm{r} \sqrt{\mathrm{n}-2}}{\sqrt{1-(r)^{2}}}$

$\mathrm{T}_{\text {hitung }}=\frac{0,576 \sqrt{6-2}}{\sqrt{1-(0,576)^{2}}}$

$\mathrm{T}_{\text {hitung }}=1,410$

karena $T_{\text {hitung }}>$ Ttabel $(1,410>0,569)$, maka $\mathrm{H}_{2 \mathrm{o}}$ ditolak sedangkan $\mathrm{H}_{2 \mathrm{a}}$ diterima, artinya persediaan terhadap laba berpengaruh.

\section{KESIMPULAN DAN SARAN}

\section{Kesimpulan}

Diperoleh hasil koefisien korelasi sebesar 0,270 yang berarti koefisien korelasinya mempunyai hubungan yang sangat rendah dan negatif.Berdasarkan perhitungan koefisien determinasi maka diperoleh sebesar 7,31\% dan sisanya 92,69\% dipengaruhi faktor lain yang tidak diteliti.Berdasarkan hasil uji hipotesisi (t), maka nilai yang diperoleh $t_{\text {hitung }}$ sebesar 0,562 digunakan uji dua pihak, artinya tidak ada pengaruh persediaan terhadap penjualan.Diperoleh hasil koefisien korelasi sebesar 0,601 yang berarti koefisien korelasinya mempunyai hubungan yang kuat dan positif.Berdasarkan perhitungan koefisien determinasi maka diperoleh sebesar $36,10 \%$ dan sisanya $63,90 \%$ dipengaruhi faktor lain yang tidak diteliti.Berdasarkan hasil uji hipotesisi (t), maka nilai yang diperoleh $t_{\text {hitung }}$ sebesar 1,503 digunakan uji dua pihak, artinya ada pengaruh penjualan terhadap 
laba.Diperoleh hasil koefisien korelasi sebesar Baridwan Zaki. 2008. Intermediate 0,576 yang berarti koefisien korelasinya Accounting. BPFE : Yogyakarta. mempunyai hubungan yang sedang dan Fahmi Irham. 2015. Pengantar Manajemen positif.Berdasarkan perhitungan koefisien Keuangan. Bandung: Alfabeta. determinasi maka diperoleh sebesar 33,20\% Riyanto Bambang. 2008. Dasar-dasar dan sisanya 66,80\% dipengaruhi faktor lain Pembelanjaan Perusahaan. Yogyakarta: yang tidak diteliti.Berdasarkan hasil uji BPFE.

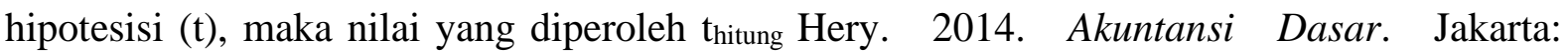
sebesar 1,410 digunakan uji dua pihak, artinya Grasindo.

ada pengaruh penjualan terhadap laba

\section{Saran}

Diharapkan agar hubungan persediaan terhadap penjualan semakin meningkat dan perusahaan dapat memperoleh keuntungan yang sangat maksimal.Adanya pengaruh yang kuat positif antara penjualan terhadap laba pada perusahaan CV. Rizky Bike Indramayu. Hal ini diharapkan dapat semakin ditingkatkan agar hubungan penjualan terhadap laba semaksimal mungkin agar perusahaan dapat memaksimalkan keuntungan. Adanya pengaruh yang sedang positif antara persediaan terhadap laba pada perusahaan CV. Rizky Bike Indramayu. Hal ini diharapkan dapat semakin ditingkatkan agar hubungan persediaan terhadap laba semaksimal mungkin agar perusahaan dapat memaksimalkan keuntungan.

\section{DAFTAR PUSTAKA}

Ambarwati, Sri Dwi. 2010. Manajeman Keuangan Lanjut Edisi Pertama. Yogyakarta: Graha Ilmu.
Kasmir. 2010. Pengantar Manajemen Keuangan. Kencana: Jakarta.

Margaretha Farah Margaretha. 2005. Teori dan Aplikasi Manajemen Keuangan. Jakarta : Grasindo

Munawir S. 2007. Analisa Laporaan Keuangan. Yogyakarta : Liberty.

R. Agus Sartono. 2008. Manajemen Keuangan Teori dan Aplikasi. Yogyakarta ; BPFE.

Sutrisno. 2012. Manajemen Keuangan dan Aplikasi. Yogyakarta; EKONISIA.

Sukirno Sadono. 2009. Mikro Ekonomi Teori Pengantar, Edisi tiga. Rajawali Jakarta : Pers.

Sugiyono. 2011. Statistik untuk Penelitian. Bandung: Alfabeta.

Sugiyono. 2013. Statistik untuk Penelitian. Bandung: Alfabeta.

Swastha Basu. 2012. Manajemen Penjualan.

Yogyakarta : BPFE.

http://library.um.ac.id http://news.palcomtech.com/wp content/uploads/Jurnal_HerlianaNovriyud iTriena_AnalisisPengaruhPerputaran.pdf 